\title{
SERO-PREVALENCE AND PREDICTIVE STATISTICAL MODEL FOR THE HEPATITIS B VIRUS EXPOSURE AMONG PEOPLE IN COMMUNITY, YASOTHON, THAILAND
}

\author{
Thanom Namwong ${ }^{1}$, Choosak Nithikathkul ${ }^{2}$, Vorapoj Promsatayaprot ${ }^{1}$ and Sumattana Glangkarn ${ }^{1}$ \\ ${ }^{1}$ Faculty of Public Health, Mahasarakham University, 44150, Mahasarakham, Thailand \\ 2 Tropical and Parasitic Disease Research Unit, Faculty of Medicine, Mahasarakham University, 44000, Mahasarakham, \\ Thailand
}

Corresponding author: Sumattana Glangkarn

Email: sumattana.g@msu.ac.th

\begin{abstract}
This study investigated the prevalence of Hepatitis $B$ virus (HBV) and identified a predictive statistical model for the HBV exposure among people in the community, Yasothon, Thailand. A cross-sectional study was performed on participants over 26 years old and living in Muang district, Yasothon province, Thailand. The research was conducted from July to August 2019. All 1,258 participants were verbally screened. Four hundred and fifty nine people were the risk group and tested for $\mathrm{HBsAg}$, and 18 cases were positive for $\mathrm{HBsAg}(3.9 \%$ [95\% Cl 3.5-4.4]). For the predictive model, the HBV exposure connected with sex, marital status, alcohol, smoking, and knowledge. The area under the receiver operating characteristics (ROC) curve was $61.8 \%(95 \% \mathrm{Cl}, 58.6$ to 65.0). At cut-off-point -0.66, the sensitivity, specificity and accuracy were $72.6 \%, 42.4 \%$ and $53.4 \%$, respectively. HBV infection was a serious health problem, it can cause cirrhosis and liver cancer in the future. The predictive model of five variables can predict risk exposure of HBV which may had other relevant factors. Verbal screening by questionnaire to classify HBsAg risk group can lower the implement cost.
\end{abstract}

Keywords: Hepatitis B virus, Seroprevalence, Predictive model

\section{INTRODUCTION}

Hepatitis B virus (HBV) caused high morbidity and mortality worldwide. World Health Organization (WHO) estimates that 257 million people were living with chronic hepatitis B infection. HBV was the main causes of liver cancer. And more than $50 \%$ of liver cancer patients had HBV. An estimated 887,000 deaths, mostly from cirrhosis and hepatocellular carcinoma ${ }^{1}$.

Thailand was an epidemic area of HBV. Approximately 10 million of the population were the carriers of HBV and those born under 1992 had an HBV infection of $4.5-5.2 \%$. It is estimated that may be the population infected with HBV of approximately $2.2-3$ million $^{2}$. High prevalence of HBV infection was those over 25 years $^{3}$. In 2013, Yasothon province found that the mortality rate of liver cancer was the 3rd highest of Northeastern Thailand, 50.3 per ten thousand people or 270 cases were liver cancer. The HBV situation in Yasothon in 2016 has been reported 45 cases, 8.3 per ten thousand population ${ }^{4}$. It is Estimated that there was more HBV infection in Yasothon.

HBV vaccine has been used in Thailand for the past 26 years. Thus, people born before 1991 didn't get the HBV vaccine which affected the high incidence of HBV infection ${ }^{2}$. In 2016, the Ministry of Public Health (MOPH) of Thailand had determined the preventive strategy of HBV, 20172021 which related with Framework for the global health sector strategy on viral hepatitis, 2016$2021^{5}$. Strategy framework included: 1) Surveillances and data development; 2) Prevention; 3) Risk communication; 4) Case finding and care; 5) Research; and 6) Resource management which the goal decreased the HBV rate. Activities focused on expanded program for immunization (EPI) promote, chronic HBV is able to access to health care more than $50 \%$ by $2021^{2}$. Thailand's Hepatitis B virus prevention strategy will be supported by the implementation of prevention and patient care to be clearer and more concrete. However, current conduction still do not have the format for drive strategies to solve the HBV problem.

In the past, HBV problem solving only conducted on health workers, men who had sex with men (MSM), sex worker, injection drug user (IDU); nevertheless, this was never implemented in the community ${ }^{2}$, especially a prevalence survey of people with HBV infection and risk behavior survey people of $\mathrm{HBV}^{4}$. Affect to health workers lacked the important data for planning to solve HBV problem. While with the risk group most was screening test and access to treatment.

This study investigated the prevalence of $\mathrm{HBV}$ and identifies the predictive statistical model for the 
HBV exposure among people in community, Yasothon, Thailand.

\section{MATERIALS AND METHODS}

\section{Settings and Design}

A cross sectional study was conducted in a community, Muang District, Yasothon Province, Thailand. It aimed to achieve the primary objective of estimating the prevalence of HBs seropositivity and to identify the predictive statistical model for the HBV exposure. The study was run during July to August 2019.

\section{Participants}

People living in the community, Muang district, Yasothon province in the present was a cross section of men and women aged 26 year or older, who born after the HBV vaccine had been used in Thailand were recruited in the study. The exclusions criteria were as follows: there were hearing problems and answering the questionnaires were not complete.

The sample size was 1,258 participants assuming a prevalence of $\mathrm{HBsAg}$ of $5 \%$, from a study that reported among the general population category ${ }^{3}$. Sample size was derived using Cochran WG's formula 6 , which estimate population proportion when the finite population the following formula: $\left(n^{0}=Z 2 \alpha / 2 Q / r 2 P, n=n^{0} / 1+n^{0} / N\right)$, where $n^{0}=$ initial sample size; $\mathrm{n}=$ sample size; $\mathrm{Za} / 2$ = standard normal distribution abscissa corresponding to $95 \%$ confidence interval (1.96); $\mathrm{P}=$ proportion of $\mathrm{HBsAg}$ reported in similar study noted above $(5 \%)^{3} ; \mathrm{Q}=$ (1-P); $r=$ relative standard error $(5 \%)$ and $N=$ populations aged 26 years or older that live in a community $(4,048)$. Simple random sampling without replacement.

\section{Collecting data and instrumentation}

The questionnaires were designed by a research team to consist of five sections: (1) demographic data, (2) other health data, (3) HBV history, (4) risk behavior of HBV, and (5) HBV knowledge. Development and psychometric testing of the questionnaire were performed. The contend validity index (CVI) was found of $0.83-1.00$ from six content experts, and the content validity of the overall scale (S-CVI) was discovered of 0.99 . After that, the bright questionnaire was tried out in 30 samples for reliability testing which found Cronbach's alpha of 0.83 .

\section{Serology}

All participants were verbally screened by the questionnaire. They were interviewed by health officers. Then, those who had the risk exposure up to 2 items, were referred to blood testing by finger test for Hepatitis B surface antigen (HBsAg). The samples who had HBsAg positive were consequently confirmed by Real-Time Polymerase Chain Reaction (RT-PCR) technic of Yasothon hospital.
Data analyzing and statistical

Data was analyzed the using Statistical Package for the Social Sciences (SPSS) software, version 18.0 (SPSS $^{\circledR}$, Chicago, USA). Descriptive statistic was used to summarize demographic data. Risk behavior or HBV exposure score was classified into two levels, two or more scores were "high risk group", less than two scores were "none or low risk group". Knowledge score was classified into three levels which included low, medium and high ${ }^{7}$. Unconditional multiple logistic regression was used to identify predictive statistical model for the HBV exposure. Independent $(x)$ variables were demographic data, knowledge, alcohol, smoking and underlying. Dependent variable $(y)$ was risk behavior from the high risk group and none or low risk group. Chi-square test was used to evaluate the bivariate relationship between the dependent variables and independent variables. The independent variables were selected with $p$ value set at $<0.25$ that suggested by Hosmer and Lemashow ${ }^{8}$ into initial regression model of multivariate analysis. Before conducted multiple logistic regression, which was an assumption test to include multi-collinearity by Variance Inflation Factor (VIF) and interaction effect that founded all independent not violated assumption. Fitted the model by backward elimination technique, the research only kept the significant variables in the final model, after that a test model was discharged by Hosmer-Lemeshow goodness-of-fit test. Identified Cut-off-point for precision of the model for predict HBV exposure was used area under the receiver operating characteristics (ROC) curve. P value <0.05 was considered significant.

\section{RESULTS}

Of the 1,258 participants, mostly were female $(60.2 \%)$, more than 45 years old $(75.2 \%)$, Single/Divorced/Widowed (75.4\%), agriculture $(68.1 \%)$ and lower secondary school (76.2\%) in table 1.

Risk behaviors toward hepatitis $B$ were high risk group (36.5). HBV knowledge mostly was at good levels $(57.6 \%)$ but was of low levels at $42.4 \%$ in table 2 .

459 participants in high risk group were $\mathrm{HBsAg}$ testing and found 18 positives $(3.9 \%$ [95\% Cl 3.54.4]). Mostly of HBsAg positive which had HBV, cirrhosis and liver cancer family history as $61.1 \%$ $(11 / 18)$ in table 3.

Bivariate analysis for select independent variable into initial regression model of multivariate analysis found six variables that $p$-value $<0.25$ and all variable had VIF value $<10$ in table 4 . 
Table 1 Demographic characteristics of the study participants $(\mathrm{N}=1,258)$

\begin{tabular}{llc}
\hline Variables & $\mathbf{n}$ & \% \\
\hline Sex & & 39.8 \\
Male & 501 & 60.2 \\
Female & 757 & 24.8 \\
Age (year) & & 75.2 \\
$26-44$ & 312 & \\
$\geq 45$ & 946 & 24.6 \\
Mean (SD), Median (min: max) $53.1(12.8), 53$ (26: 96) & & 75.4 \\
Marital status & & 68.1 \\
Married/Partnered & 309 & 17.7 \\
Single/Divorced/Widowed & 949 & 14.2 \\
Occupation & & \\
Agriculture & 856 & 76.2 \\
Employed & 223 & 23.8 \\
Unemployed & 179 & \\
Education & & \\
Lower secondary school & 958 & \\
Secondary school and upper & 300 & \\
\hline
\end{tabular}

Table 2 Risk behaviors toward hepatitis B and hepatitis B knowledge $(N=1,258)$

\begin{tabular}{lcc}
\hline Variables & $\mathbf{n}$ & $\mathbf{\%}$ \\
\hline Risk behaviors of HBV & 799 & 63.5 \\
Low or None & 459 & 36.5 \\
High & & \\
HBV knowledge & 533 & 42.4 \\
Good $(\geq 60 \%)$ & 725 & 57.6 \\
Low $(<60 \%)$ & \\
\hline
\end{tabular}

Table 3 Prevalence of Hepatitis B virus (HBV) stratified by member of family was HBV/Cirrhosis/Liver cancer

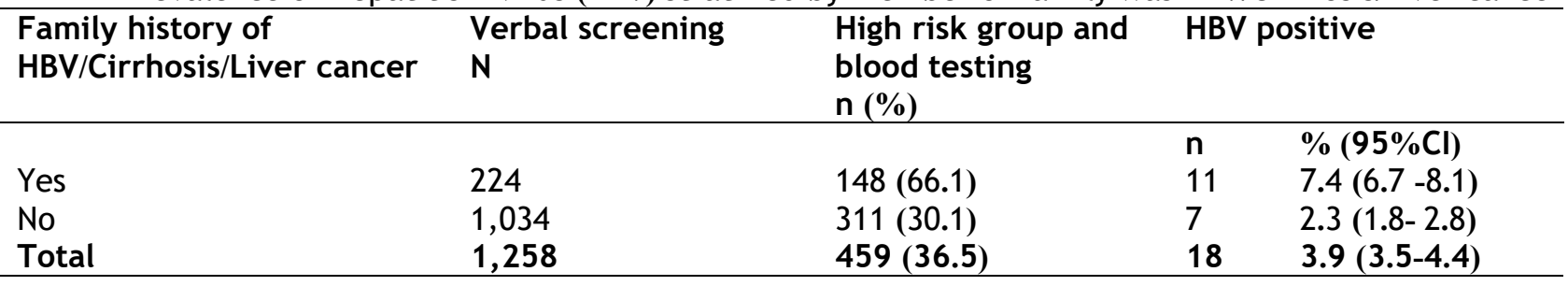

Multivariate analysis by Unconditional multiple logistic regression, the final model found five factors associated with HBV exposure include sex (Adjusted OR 2.0, 95\% Cl 1.4 to 2.8 ), marital status (Adjusted OR 1.5, $95 \% \mathrm{Cl} 1.1$ to 1.9), alcohol (Adjusted OR 1.6, 95\% 1.2 to 2.0), smoking (Adjusted OR 1.5, $95 \% \mathrm{Cl} 1.1$ to 2.2 ), and knowledge (Adjusted OR 1.7, $95 \% \mathrm{Cl} 1.3$ to 2.1 in table 5 .

Model testing by Hosmer-Lemeshow goodness-offit test (GOF), $p$ value 0.241, the area under the receiver operating characteristics (ROC) curve were $61.8 \%(95 \% \mathrm{Cl}, 58.6$ to 65.0$)$. At cut-offpoint-0.66, the sensitivity was $72.6 \%$, the specificity was $42.4 \%$, and the accuracy was $53.4 \%$ in figure 1 . For the predictive model of five variables can be predicted the risk exposure of HBV was $\mathrm{P}(\mathrm{Y}=1 / \mathrm{X})=1 /[1+\mathrm{EXP} \quad(-1.72+0.69$ Sex(male) + 0.37 Status(Single/Divorced/Widowed) +0.44 Alcohol (drink) +0.42 Smoking +0.52 Knowledge]

\section{DISCUSSION}

HBV infection was a serious health problem in Yasothon province. Despite the recent data demonstrated a prevalence rate less than the prevalence estimated from Thailand, a prevalence rate higher than some studies ${ }^{3}$. The result of this study showed that people in the community were a risk group to HBV infection similar prevalence of general population. Also, $\mathrm{HBV}$ infection to have a higher prevalence in those who have family history of HBV infection. Many studies mentioned that people who had the family history of HBV, cirrhosis and liver cancer are high risk populations for HBV infection ${ }^{9,10,11}$. These can affect to increase for HBV chronic, cirrhosis and liver cancer in the future ${ }^{1,13}$. Suh et $\mathrm{al}^{14}$ reported that HBV was the main causes of liver cancer. And more than $50 \%$ of liver cancer patients had HBV. Liver cancer is the sixth most common cancer worldwide. About $83 \%$ occurred in less developed countries, and the highest incidence was observed in Asia and Africa ${ }^{14}$. 
Tables 4 Factors associated with HBV exposure (Bivariate analysis) $(\mathrm{N}=1,258)$

\begin{tabular}{|c|c|c|c|c|c|}
\hline Factors & $\mathbf{N}$ & $\begin{array}{l}\text { High risk group } \\
\mathrm{n}(\%)\end{array}$ & Crude OR & $95 \% \mathrm{Cl}$ & P-value \\
\hline Sex & & & & & 0.009* \\
\hline Female & 757 & $298(39.4)$ & & & \\
\hline Male & 501 & $161(32.1)$ & 1.4 & $1.1,1.7$ & \\
\hline Age & & & & & 0.484 \\
\hline 26-44 year & 312 & $119(38.1)$ & & & \\
\hline$\geq 45$ year & 946 & 340 (35.9) & 0.9 & $0.9,1.9$ & \\
\hline Status & & & & & $0.004 *$ \\
\hline Married/Partnered & 949 & $325(34.2)$ & & & \\
\hline $\begin{array}{l}\text { Single/Divorced/Widowed } \\
\text { Education }\end{array}$ & 309 & $134(43.4)$ & 1.5 & $1.1,1.9$ & 0.533 \\
\hline Less than middle school & 958 & $345(36.0)$ & & & \\
\hline Since middle school & 300 & $114(38.0)$ & 1.1 & $0.8,1.4$ & \\
\hline Occupation & & & & & $0.065 *$ \\
\hline Agriculture & 859 & $302(35.2)$ & & & \\
\hline Employed & 220 & $81(36.8)$ & 1.1 & $0.8,1.5$ & \\
\hline Unemployed & 179 & $76(42.5)$ & 1.4 & $0.9,1.9$ & \\
\hline $\begin{array}{l}\text { Underlying } \\
\text { (DM/HT/Heart/ kidney) }\end{array}$ & & & & & 0.319 \\
\hline No & 836 & $297(35.5)$ & & & \\
\hline Yes & 422 & $162(38.4)$ & 1.1 & $0.9,1.4$ & \\
\hline Smoking & & & & & $0.074 *$ \\
\hline No & 901 & $315(35.0)$ & & & \\
\hline Yes & 357 & $144(40.3)$ & 1.3 & $0.9,1.6$ & \\
\hline Alcohol drinking & & & & & $0.018 *$ \\
\hline No & 587 & $194(33.0)$ & & & \\
\hline Yes & 671 & $265(39.5)$ & 1.3 & $1.0,1.7$ & \\
\hline HBV knowledge & & & & & $<0.001 *$ \\
\hline Good $(\geq 60 \%)$ & 533 & $160(30.0)$ & & & \\
\hline Low $(<60 \%)$ & 725 & $299(41.2)$ & 1.6 & $1.3,2.1$ & \\
\hline
\end{tabular}

*variables are $\mathrm{p}$ value $<0.25$ to initial model of multiple logistic regression

Table 5 Predictive statistical model for the risk behaviors toward hepatitis B (Multivariable analysis by multiple logistic regression) $(\mathrm{N}=1,258)$

\begin{tabular}{|c|c|c|c|c|c|c|c|}
\hline \multirow[t]{2}{*}{ Variables } & \multirow[t]{2}{*}{ Co-efficient } & \multirow[t]{2}{*}{ SE } & \multirow[t]{2}{*}{ Crude OR } & \multirow[t]{2}{*}{ Adj. OR } & \multicolumn{2}{|c|}{$95 \% \mathrm{Cl}$ for $\mathrm{OR}_{\mathrm{adj}}$} & \multirow[t]{2}{*}{ P-value } \\
\hline & & & & & Lower & Upper & \\
\hline Sex (male) & 0.69 & 0.17 & 1.4 & 2.0 & 1.4 & 2.8 & $<0.001$ \\
\hline $\begin{array}{l}\text { Marital status } \\
\text { (Single/Divorced/Widowed) }\end{array}$ & 0.37 & 0.14 & 1.5 & 1.5 & 1.1 & 1.9 & 0.007 \\
\hline Alcohol & 0.44 & 0.13 & 1.3 & 1.6 & 1.2 & 2.0 & 0.001 \\
\hline Smoking & 0.42 & 0.19 & 1.1 & 1.5 & 1.1 & 2.2 & 0.025 \\
\hline HBV knowledge (low) & 0.52 & 0.12 & 1.6 & 1.7 & 1.3 & 2.1 & 0.001 \\
\hline Constants & -1.72 & 0.19 & - & - & - & - & - \\
\hline
\end{tabular}

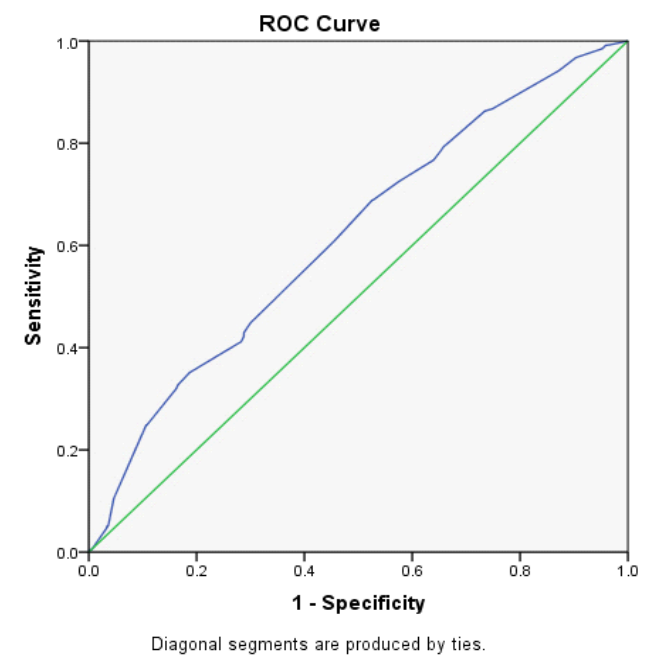

Figure 1. Area under the receiver operating characteristics (ROC)
Verbal screening by questionnaire for classified risk group into $\mathrm{HBsAg}$ testing in this study can decrease a cost for the implementation. HBV vaccination for persons who did not have the immune and HBsAg testing in the risk group to be cost-effective. Therefore, these referred to treatment or health-promoting ${ }^{14,15}$.

The predictive model of five variables can predict the risk exposure of HBV significantly including sex, marital status, alcohol, smoking and knowledge.

Males had the risk exposure more than females because males had a chance to show off sex behavior such as they had a tattoo and sex with multiple partners. In a study carried out in blood donors by Torre et $\mathrm{al}^{16}$ and Xaydalasouk et $\mathrm{al}^{17}$ 
show that people who have multiple partners or history of sexual risk behaviors are associated with HBV infection.

The subjects who had marital status single, divorced and widowed seemed to have the risk exposure more than those who had married, may be those who did not have a regular partner, could be having sex with another partner. The study carried out by Pereira et $\mathrm{al}^{10}$ showed significant association with married status.

Moreover, those who used smoking, alcohol drinking and low HBV knowledge will have an increased chance to expose the risk of HBV similar findings were reported from Ataei et $\mathrm{al}^{9}$ and Frew et $\mathrm{al}^{17}$. On the other hand, those who don't smoke or drink alcohol and have a high knowledge will have a decreased chance to expose the risk of HBV $^{18,19}$

Hosmer-Lemeshow goodness-of-fit test (GOF) and the area under the receiver operating characteristics (ROC) showed that if the model was fit, predicted the risk exposure of HBV were at a poor level but $95 \% \mathrm{Cl}$ of $\mathrm{ROC}$ that the narrow showed the model was precise. Sensitivity value was fair, even specificity and accuracy value to be fail ${ }^{20}$. However, the model can be used to plan for HBV prevention, especially using screening for health promoting and $\mathrm{HBsAg}$ testing which were cost-effective ${ }^{14}$.

A highly effective program for universal immunization was implemented in Thailand more than two decades ago. However, a large number of individuals infected with HBV were born earlier and people live in community are one of important risk group. The high burden of HBV in Yasothon province still is a major challenge for the incorporation of programs to prevent HBV complications within health care systems such as the development the surveillance system in order for early detection and refer people with HBV infection to be treated. While educational programs for health must focus in particular on the prevention of people who had the family history of HBV, cirrhosis and liver cancer.

\section{LIMITATION}

This study conducted among people in community who lived in the Northeast maybe have a difference about culture. Therefore, they should be careful when using the finding from this study for implantation in other risk groups.

\section{SUGGESTIONS}

Heath officer can use the finding from this study for application into HBV prevention. And they can also bring the questionnaire to verbal screening the risk group of HBV. Next study, should be a study of other factors that associates with HBV. And follow people that had HBsAg positive that became cirrhosis and liver cancer.

\section{ACKNOWLEDGEMENT}

The authors would like to thanks Miss. Narisara Arrirak, Community leaders, Health volunteers and Health officers of Nong-Khu health promoting sub-district for supported the data collected on this study.

\section{Conflict of interest}

The authors have no conflicts of interest to declare.

\section{Ethical approval}

The present study was approved by Human Research Ethics Committee of the Mahasarakham University (protocol number 058/2019). Patients were enrolled after written informed consent.

\section{REFERENCE}

1. World Health Organization(WHO) [Internet]. Hepatitis B/Key facts [cited 2020 July 27]. Available from: https://www.who.int/newsroom/fact-sheets/detail/hepatitis-b

2. Yanwetsakun $P$, Siriwongrangsan $P$, Sutthiwat SC, Tangprasertsuk S. Prevention strategy of hepatitis B virus of Thailand 2017-2021; JS printing: 2017.

3. Leroi C, Adam P, Khamduang W, Kawilapat $S$, Ngo-Giang-Huong $N$, Ongwandee $S$, et al. Prevalence of chronic hepatitis $B$ virus infection in Thailand: a systematic review and meta-analysis. Int J Infect Dis 2016; 51: 36-43.

4. Silarak K, Namwong T. An Evaluation of Hepatitis B viral surveillance, Yasothon province, Thailand, January 2014December 2016. Weekly Epidemiological Surveillance Report 2017; 48(49): 769-76.

5. World Health Organization (WHO) [Internet]. Global Health Sector Strategy on Viral hepatitis 2016-2021. Geneva, Switzerland: the WHO Document Production Services 2016. [cited 2019 Feb 20]. Available from: https://www.who.int/hepatitis/strategy201 6-2021/ghss-hep/en/

6. Cochran WG. Sampling techniques. 3rd ed. Biostatistics. New York: John Wiley \& Son; 1977.

7. Best JW. Research in Education. New York: Prentice-Hall, Englewood Cliffs; 1977.

8. Hosmer DW, Lemashow S. Applied Logistic Regression. 2nd ed. New York: A Wiley Interscience Publication; 2000. 
9. Ataei B, Alavian SM, Shahriari-Fard F, Rabiei A A, Safaei A, Rabiei A. A case-control study of risk factors for hepatitis $B$ infection: $A$ regional report among Isfahanian adults. J Res Med Sci 2019; 24: 22.

10. Pereira VRZB, Wolf JM, da Silva-Luz CM, Stumm GZ, da Rocha-Boeira T, Galvan J, Simon D, Lunge VR. Risk factors for hepatitis $B$ transmission in South Brazil. Mem Inst Oswaldo Cruz, Rio de Janeiro 2017; 112(8): 544-50.

11. Bauer-Staeb C, Jorgensen L, Lewis G, Dalman C, Osborn DPJ, Hayes JF. Prevalence and risk factors for HIV, hepatitis $B$, and hepatitis $C$ in people with severe mental illness: a total population study of Sweden. The Lancet Psychiatry 2017; 4(9): 685-93.

12. Zhou Y, Wan Y, Ye ZW, He Z, Liu Q, Shi Y. How Hepatitis B virus causes cirrhosis and liver cancer. Medical Hypotheses 2017; 108: 52-53.

13. Suh JK, Lee J, Lee J-H, Shin S, Tchoe $\mathrm{Hj}$, Kwon J-W. Risk factors for developing liver cancer in people with and without liver disease. PLoS ONE 2018; 13(10): 1-13.

14. Tantai $N$, Werayingyong $P$, Leelahavarong $\mathrm{P}$, Teerawattananon Y. Cost-utility analysis of screening for hepatitis $B$ viral infection in Thailand. Health Systems Research Institute (HSRI) journal 2013; 7(4): 440-51.

15. Kao JH. Hepatitis B vaccination and prevention of hepatocellular carcinoma. Best Practice and Research: Clinical Gastroenterology 2015; 29(6): 907-17.

16. Torre GL, Saulle R. Risk factors from HBV infection among blood donors: A systematic review. Asian Pac J Trop Biomed 2016; 6(4): 344-9.

17. Frew G, Mc George E, Grant S, Wildt G. Hepatitis B: A cross-sectional survey of knowledge, attitudes and practices amongst backpackers in Thailand. Travel Medicine and Infectious Disease 2017; 15: 57-62.

18. Xaydalasouk K, Strobel M, Buisson $Y$, Black AP, Muller CP. Seroprevalence and risk factors of hepatitis $B$ and $C$ virus infections in female workers of Lao garment factories. PLOS ONE 2018; 13(7): 1-8.

19. Rajamoorthy $Y$, Taib NM, Mudatsir M, Harapan $\mathrm{H}$, Wagner AL, Munusamy S, Rahim KA, Radam A. Risk behaviours related to hepatitis $B$ virus infection among adults in
Malaysia: A cross-sectional household survey. Clinical Epidemiology and Global Health 2020; 8: 76-82.

20. Greiner M, Pfeiffer D, Smith RD. Principles and practical application of the receiveroperating characteristic analysis for diagnostic tests. Preventive Veterinary Medicine 2000; 45: 23-41. 